\title{
Cidades representadas: uma reflexão acerca dos estudos sobre imprensa e cidade no Brasil do pós-guerra
}

Represented cities: a reflection on studies of the press and city in Brazil Postwar Ciudades representadas: una reflexión sobre los estudios de la prensa y de la ciudad en Brasil

Luis Carlos dos Passos Martins*

\section{Resumo}

O presente artigo faz uma análise do tema dos estudos sobre imprensa e história no Brasil, abordando o período do pós-guerra, quando o país passou por profundas transformações urbanas. Considera-se que as pesquisas na área avançaram muito nos últimos anos, abordando as mudanças nas principais cidades brasileiras durante a Belle Époque (projeto higienista). Entretanto, aponta-se que tais pesquisas não abarcam outros períodos relevantes, como o pós-guerra, e que elas tendem mais à análise empírica do que à teorização da relação imprensa e cidade. $\mathrm{O}$ trabalho aqui exposto, a partir dos conceitos de representação social, de Roger Chartier, e de lutas simbólicas, de Pierre Bourdieu, procura promover uma reflexão teórica sobre a importância do estudo da im- prensa na compreensão da dinâmica urbana em processo de transformação.

Palavras-chave: Cidade. Imprensa. Representação.

\section{Introdução}

Tal como nós a conhecemos hoje, a imprensa é fundamentalmente produto do urbano na medida em que foi nas cidades que ela encontrou o ambiente favorável (concen-

\footnotetext{
Doutor em História pela Pontifícia Universidade Católica do Rio Grande do Sul, Brasil. Pós-doutorado em História pela Pontifícia Universidade Católica do Rio Grande do Sul. Professor adjunto da Pontifícia Universidade Católica do Rio Grande do Sul.
}

Recebido em 01/04/2016 - Aprovado em 01/09/2016 http://dx.doi.org/10.5335/hdtv.16n.2.6926 
tração de leitores, disponibilidade de renda, recursos tecnológicos acumulados, mercado de anunciantes, etc.) para emergir e prosperar. Da mesma forma, o urbano e a urbanidade tiram parte das suas características da relação com os meios de comunicação, pois as formas como a cidade é percebida e, mesmo se percebe, são normalmente mediadas pela comunicação massiva.

Não surpreende, dessa maneira, que estudos sobre o tema cidade e imprensa tenham aumentado nos últimos anos na historiografia brasileira. Na base disso está a valorização da "cidade" como objeto de estudo historiográfico, especialmente nas pesquisas sobre os processos de "higienização" das principais capitais brasileiras (XIX - XX). Também influencia o processo a (re)consideração da imprensa como fonte de pesquisa para temas como o aqui abordado. Produzidos com regularidade mensal, semanal e mesmo diária, jornais e revistas destinam suas páginas a assuntos contemporâneos, dando espaços a tópicos diversos, como os problemas urbanos (trânsito, fornecimento de energia, água, alimentação, criminalidade, moradia, etc.) e relatos do cotidiano. Também figuram com destaque classificados, anúncios variados e inúmeros textos de opinião sobre a vida na cidade (artigos, editoriais, crônicas). Todo esse "oceano" de informações, narrativas e interpretações acerca do "viver urbano" não poderia ser negligenciado por uma historiografia que se interessa cada vez mais pelo estudo das mentalidades, subjetividades e sensibilidades individuais e/ou coletivas. Essa grande variedade de temáticas torna a imprensa fonte privilegiada para as indagações sobre o urbano e suas transformações no Brasil. Movimento que se intensificou com a penetração da Escola dos Anais no país, em especial, no que se refere à sua terceira geração, conhecida como História Cultural.

Os estudos iniciais sobre o tema deram origem a uma forte tradição de análise, em muito motivada pela qualidade de seus principais historiadores. Produzidos majoritariamente entre os fins dos anos de 1990 e início de 2000, esses estudos tiveram como protagonistas pesquisadores consagrados no país, que redigiram diretamente algumas das mais importantes obras - Sandra Pesavento (2002), Sevcenko (2006), Marialva Barbosa (2007), Ana Maria Martins e Tânia de Lucca (2008) e Heloísa Cruz (2013) - ou trabalharam na sua organização - Sandra Pesavento e Célia Souza (2008), Stella Bresciani (2001) e Lúcia Lippi de Oliveira (2002). Em termos de conteúdo, essas pesquisas focaram-se essencialmente na Belle Époque e nas transformações derivadas do processo de "higienização" das principais cidades brasileiras. A preocupação básica eram, e ainda são, os planos de urbanização de um Brasil que se modernizava orientado pela Paris de Haussmann e os diversos espaços de vivências urbanas, como a vida cotidiana e a exclusão da cidade de negros, pobres, etc.

Apesar da importância e do pioneirismo dessas pesquisas, elas deixaram algumas lacunas. Se as pesquisas centradas no higienismo da Belle Époque trouxeram muitos avanços para o conhecimento do tema, elas acabaram gerando, menos que indiretamente, um vácuo nos estudos para outros 
momentos da história brasileira. Como é o caso do pós-Segunda Guerra Mundial, especialmente nos anos 1950 e 1960. Nesse período, o Brasil passou por enormes mudanças demográficas, apresentando, além do significativo aumento do seu contingente populacional, ${ }^{1}$ uma notável aceleração da urbanização, impulsionada pela industrialização (SINGER, 1985; OLIVEN, 1988).

Além de rápida, essa mudança foi bastante drástica e complexa. A acelerada urbanização pode, por um lado, ter fascinado pela considerável modernização das cidades - com a emergência dos arranha-céus, a abertura de novas avenidas e a própria presença maciça do automóvel -, porém, ela também provocou reações contrárias, especialmente diante das inúmeras mudanças e problemas que acarretou (ABREU, 1987; OLIVEN, 1988; ALMEIDA, 2011). Em relação a isso, devem ser salientadas as modificações urbanísticas que tentaram adaptar as cidades brasileiras às demandas por infraestruturas exigidas pela industrialização - como a reformulação do sistema viário e do fornecimento de energia (ABREU, 1987). Também chama a atenção a enorme migração humana provocada pelo êxodo rural, que acarretou a instalação e ampliação de vilas operárias, mas também o aumento significativo das habitações irregulares classificadas como "favelas". Além disso, esse processo implicou, afora do aumento das "favelas", também uma mudança na composição étnica da população urbana, com incremento exponencial dos grupos de ascendência africana e indígena em detrimento das camadas de origem europeia (ABREU, 1987; OLIVEIRA, 2002; SINGER,
1985; PATARRA, 1986). Por fim, deparamo-nos com diversos problemas urbanos como a ampliação das deficiências de transporte urbano, abastecimento de água e de energia que caracterizaram as cidades brasileiras, especialmente entre as décadas de 1950-1960 (MORAES, 2011).

Em síntese, temos um processo interessantíssimo para ser avaliado, especialmente no que se refere à recuperação das visões e vivências a eles associadas, que, contudo, ainda foi pouco explorado.

Outro ponto que chama atenção nos trabalhos mais recentes sobre imprensa e cidade é a tendência por um viés mais narrativo e empírico do que analítico e teórico. $\mathrm{Ou}$ seja, apesar dos grandes avanços e de algumas iniciativas pontuais de reflexão conceitual, carecemos de textos que explorem mais a fundo as potencialidades de pesquisa que o tema apresenta.

É nesse sentido que pretendemos fazer uma contribuição ao propor uma reflexão teórica sobre o uso da imprensa como fonte e objeto de pesquisa para a história das cidades, tendo como foco uma realidade histórica de rápidas transformações urbanas, como foi o caso do Rio de Janeiro e de São Paulo no pós-guerra. Para isso, partir-se-á do conceito de representação social - desenvolvido especialmente por Roger Chartier - e de luta simbólica - proposto por Pierre Bourdieu, com acréscimos dos estudos sobre mediação e polifonia, respectivamente, de Mantin-Barbero e de Mikhail Bakhtin. 
Representação social e representação do

\section{espaço: uma aproximação}

O conceito de representação origina-se da palavra latina repreasentare, cujo significado original era a ideia de reapresentar, ou seja, apresentar uma coisa ou pessoa no lugar de outra coisa ou pessoa que não poderia estar presente (PITKIN, 2006, p. 18). Em outras palavras, representação implica em uma substituição "simbólica" de algo que, por princípio, não está apto a se materializar em determinadas condições espaço-temporais (GUINZBURG, 2001). Dessa maneira, ela envolve necessariamente um processo de mediação que comporta a existência de complicados mecanismos de substituição, não totalmente isentos de contradições e simplificações.

Na passagem do século XIX para o XX, o conceito de representação irá ser apropriado pela sociologia no trabalho do francês Émile Durkheim, que desenvolve a noção de "representações coletivas". ${ }^{2}$ Para ele, as representações coletivas são "formas simbólicas" compartilhadas socialmente, e que funcionam como categorias de compreensão da realidade, pelos membros da comunidade que as desenvolvem. Tais categorias têm origem na própria estrutura social, mas não são meros reflexos de um social previamente existente a sua "expressão simbólica". Ao contrário, embora condicionado por elementos objetivos da realidade, o processo de representação coletiva é essencial para que o social tenha estabilidade e permanência, logo, que "exista coletivamente" (DURKHEIM, 1996). Em outras palavras, embora as representações coletivas sejam condicionadas pela sociedade, elas são "símbolos" que materializam, dão unidade e, nos termos de Durkheim, sintetizam o social, que só ganha unidade de sentido em uma expressão simbólica separada e diferente dele.

Essas proposições de Durkheim serão seguidamente retomadas e ganharão uma nova funcionalidade com Pierre Bourdieu e, especialmente, com Roger Chartier. Esse último irá apropriar-se do conceito de representação para superar a dicotomia da historiografia dos anos 1970/1980 entre, de um lado, o que ele chama de "tirania do social", ou seja, as abordagens que consideram a sociedade como uma realidade pré-simbólica (materialismo histórico) e, de outro lado, o império da cultura, ou melhor, as interpretações fundadas na escola interacionista norte-americana, que procura ver a cultura de forma isolada, dotada de uma lógica própria e independente da realidade social (CHARTIER, 2002). Chartier, porém, vai se afastar de Durkheim, através do conceito de representações sociais. Para o autor, as "representações coletivas" compartilham, como conceito, o mesmo problema das mentalidades: ser uma noção geral que não comportava adequadamente as diferenças sociais que se constroem por intermédio do simbólico. Dessa maneira, junto com a noção de representações sociais, Chartier também desenvolve o conceito de "lutas de representação", análogo e inspirado na ideia de "luta simbólica" proposta por Bourdieu.

Bourdieu defende que o mundo social é constituído de uma realidade pré-linguística composta por um conjunto plural e contraditório de elementos objetivos potenciais 
- como as diferenças de raça, de grau de instrução, da região de origem ou de moradia, etc. -, que têm potencial de servir de referência para a divisão dos indivíduos em grupos. Tais "referentes", porém, não possuem um significado imanente e, enquanto plurais e contraditórios, podem dar origem a diferentes formas de agrupamentos, cujos contornos e significações são definidos pelo de representação (BOURDIEU, 1987, 1990). Para Bourdieu (1979, 1990), o trabalho de representação não é "neutro": as representações sociais são também formas de valoração e, assim, de hierarquização da sociedade. Isto, porém, não ocorre em um "vazio" e tem como base as possíveis diferenças objetivas na realidade, que, contudo, só ganham sentido por meio das representações. É pelas representações que conjuntos de indivíduos, apresentando acesso diferenciado a determinados bens materiais ou culturais, são hierarquizados simbolicamente e, assim, legitimados ou deslegitimados (BOURDIEU, 1979).

Esse processo, entretanto, não é automático e nem passivo. Longe disso, ocorre mediante uma verdadeira disputa entre os grupos sociais e entre os profissionais especializados na produção de bens simbólicos, que o autor conceitua como "luta simbólica": a luta pela definição da visão mais legítima sobre o mundo social, que é também um conflito pela construção desse mundo, porque a transformação ou a conservação da ordem social depende da transformação ou conservação dos esquemas de percepção dessa ordem. Nessa luta, os agentes podem investir todos os recursos que dispõem ( $c a-$ pital), mas o peso maior fica por conta do que o autor chama de capital simbólico, capital de prestígio ou autoridade socialmente reconhecida.

Essa forma de capital, os agentes (indivíduo ou instituição) retiram de suas aquisições em lutas anteriores e ela lhes permite um poder de sanção sobre o que está em jogo na disputa (BOURDIEU, 1989, p. 134).

Essas considerações sobre o aporte teórico de Chartier e Bourdieu são particularmente elucidativas sobre o objeto que se pretende estudar: a percepção sobre as mudanças no cenário urbano brasileiro do pós-guerra. Realidades socioeconômicas em rápidas e drásticas transformações são particularmente sujeitas a gerar ou mesmo exigir esquemas mentais diferentes para se tornarem compreensíveis, oferecendo um terreno fértil para as "lutas de representação". A nova realidade que emerge pode gerar expectativas e esperanças, mas também ser objeto de inquietações e temores. Isso normalmente instiga a reflexão, colocando em xeque formas tradicionais de ver a realidade, ao mesmo tempo que incita novas (BOURDIEU, 1996).

Essas considerações têm especial valor quanto tratamos de transformações na ocupação do espaço, que tendem a produzir igualmente transformações nas representações desse espaço. Como salienta Bourdieu, por mais que o espaço físico possa ter características objetivas, sua representação não é algo imediato e natural, passa pelo mesmo processo de simbolização que vimos em relação ao espaço social.

Essas reflexões são de fundamental importância para pensarmos a cidade e sua simbolização espacial. Com efeito, os centros 
urbanos - por suas variações econômico-sociais e por sua diversidade étnica, cultural, etc. - são universos plurais e contraditórios e, por isso, polissêmicos (BRESCIANI, 2001). A cidade pode ser vista das mais diferentes maneiras e, assim, o que ela pode significar não deriva apenas da experiência empírica subjetiva de cada um, mas igualmente das formas como a urbs é representada simbolicamente. Essas formas de representação também são formas de hierarquização do espaço e, dessa maneira, dos grupos sociais que os habitam (BOURDIEU, 1996), dividindo as cidades em zonas de habitação legítimas e legitimadoras (os bairros chiques) e zonas de moradia ilegítimas/desprestigiantes (a periferia, o subúrbio e, no caso brasileiro, a favela).

Dentro da análise acima exposta, qual o lugar dos meios de comunicação e, em particular, da imprensa? Bourdieu insere o papel dos jornais no interior daquilo que conceitua como campo de produção ideológica (CPI):

universo relativamente autônomo, onde se elaboram, na concorrência e no conflito, os instrumentos de pensamento do mundo social objetivamente disponíveis a um momento dado do tempo e onde se define, simultaneamente, o campo do pensável politicamente ou, se quiser, a problemática legítima (1979, p. 465).

Dessa maneira, o campo de produção ideológico é um espaço de conflito no qual se disputa a visão mais legítima sobre os assuntos politicamente relevantes no debate público. Além disso, para Bourdieu, o CPI, assim como qualquer campo de produção simbólica, exerce uma função ideológica, ou seja, tem papel significativo no processo de encobrimento das diferenças sociais objetivas que dão base à estrutura de uma sociedade dividida em classes (BOURDIEU, 1994).

Os meios de comunicação têm, para o autor, um espaço particular nesse universo. Se, por um lado, segundo o autor, os jornalistas ocupariam uma posição inferior diante dos demais produtores de bens simbólicos, na medida em que dependem dos últimos para produzir o bem que oferecem (BOURDIEU, 1987, p. 156), por outro lado, porém, recebem sua força do (quase) monopólio dos meios de grande difusão que lhes permitem um grande poder de influência sobre todos os produtores dependentes de sua "imagem pública" e, assim, do "acesso" ao grande público (BOURDIEU, 1994, p. 7). Dessa maneira, os meios de comunicação são o espaço privilegiado quando desejamos identificar as ideias, os projetos e as representações que efetivamente circularam por determinada coletividade, para além do círculo restrito dos produtores de bens simbólicos.

Mas, para Bourdieu, esses meios não são meras instâncias reprodutivas dos discursos sobre o social que se produzem fora deles. Por ser um campo com baixo poder de autonomia, ${ }^{3}$ o jornalismo, historicamente, obrigou-se a lutar por formas próprias de inserção institucional no debate público. A principal delas foi a adotada pela imprensa anglo-saxônica, na estratégia de se firmar como instância especializada na oferta confiável de informações. Além da condição de "fonte confiável de informação", o jornalismo anglo-saxão historicamente também 
tentou construir sua inserção na "arena de debates" como uma instância fiscalizadora dos agentes públicos em nome do leitor-cidadão, representando a si mesmo como o "quarto poder" (CHALABY, 2003).

Segundo alguns autores, como Chalaby (2003) e Ferenczi (1993), o jornalismo francês seguiu outro caminho, transformando a imprensa em uma espécie de "tribuna de opinião", por meio da qual os jornais procuravam se colocar como defensores do "interesse público", porém, com base em bandeiras doutrinárias e campanhas "coletivas", procurando exercer um papel de "intérprete da realidade" para seu público leitor. Além disso, devemos considerar que, mesmo procurando buscar a maior extensão possível de seu público leitor, o jornalismo sempre se constituiu como um campo cujos bens tendem a ser socialmente direcionados. Seus temas, o estilo de linguagem, a diagramação das suas páginas e mesmo as visões e interpretações do mundo que apresentam são socialmente condicionadas e fragmentadas, tendendo a se dirigir e agradar aqueles que se sentem representados e/ ou familiarizados com o universo intelectual oferecido por determinado jornal.

Uma das principais divisões internas no campo jornalístico ocorre pela sua constituição em torno da oposição entre os jornais que oferecem, acima de tudo, as 'novidades', preferencialmente 'sensacionais', ou melhor, 'a sensação', e os jornais que propõem análises e comentários, procurando marcar sua diferença em relação aos primeiros, afirmando os valores da 'objetividade' (BOURDIEU, 1994, p. 4). Esses diferentes impressos tendem a se direcionar a leitores específicos: os "sensacionalistas" voltando-se aos leitores com menor volume de capital econômico e cultural, enquanto que os "jornais de análises" cooptam clientela nos extratos superiores da hierarquia social. Além disso, mesmo nesses dois polos, podemos encontrar variações, com periódicos apresentando, por exemplo, opiniões mais à esquerda ou à direita do campo político e, assim, dividindo-se entre leitores com maior capital cultural, para o primeiro caso, e com maior capital econômico, para o segundo (BOURDIEU, 1979, p. 464).

Bourdieu, contudo, não vê esse "casamento" entre jornais/jornalistas, público e anunciantes como mero efeito da "manipulação". Ao contrário, para ele, essa relação tende a se dar de forma espontânea por um conjunto de escolhas dos agentes envolvidos baseadas em seus habitus de classe, ou seja, os jornalistas oriundos de determinado extrato social tendem a se empregar em jornais destinados a públicos com a mesma origem social, com os quais compartilham certas preferências, gostos e visões de mundo, estando socialmente destinados a agradar os "seus semelhantes" (BOURDIEU, 1979, 1994).

A aplicação desses conceitos bourdianos para o Brasil, porém, é problemática e exige algumas adaptações. Primeiramente, devemos lembrar que a imprensa brasileira dos anos 1940 aos 1960 era influenciada pelo exemplo francês, combinando diferentes "modelos" de jornalismo. Predominava, contudo, "um jornalismo 'de missão', comprometido politicamente e convencido do poder de sua 'tribuna' sobre a opinião pública" (ALDÉ, 1997, p. 29). Nesse mesmo 
período, os grandes jornais brasileiros vão passar por uma forte transformação, adotando o modelo de imprensa anglo-saxônico. Muito embora, como apontam algumas análises (RIBEIRO, 2007; GOLDENSTEIN, 1987), essa incorporação tenha sido bastante limitada e orientada, mais por interesses políticos do que econômicos, ela transformou a face do jornalismo nacional, que se viu obrigado a lidar com novas regras de produção da informação, diferentes daquelas da "imprensa de tribuna" (ABREU; LATTMAN-WELTMAN, 1994). Em outras palavras - e isso é importante guardar -, os jornais brasileiros no período aqui em estudo passaram por um processo de rápida mudança paralela e correlata às transformações ocorridas nas cidades, modernizando as suas linhas editoriais e a sua condição como empresas de comunicação.

Essas considerações são fundamentais para a compreensão do objeto de pesquisa aqui definido e delimitado. A partir delas, dispomos de uma nova forma de interpretar o papel da imprensa como agente histórico, abandonando a tendência de concebê-la apenas como suporte do discurso de outros poderes ou setores da sociedade. Embora não estejam isentos da pressão desses campos, jornais e jornalistas igualmente apresentam interesses próprios, participam do jogo de poder e influência. Em outras palavras, a representação que o jornalismo faz da realidade não pode ser reduzida nem a mero reflexo do real (ideologia da profissão) nem à pura manipulação em prol de interesses políticos e econômicos que se exerceriam de fora dele. Há a necessidade de se incorporar na análise as formas próprias com que essa área de produção cultural vê e representa o mundo social.

Por fim, é importante acrescentar um ponto que consideramos compatível com as abordagens de Bourdieu e que pode ser recuperado a partir da obra de Martin-Barbero (1997). Na perspectiva desse autor, um texto jornalístico não pode ser compreendido apenas como uma mensagem emitida de cima para baixo diante de um receptor passivo. Ao contrário, além de o "receptor" também ser considerado um "produtor" da mensagem na sua leitura ativa, a própria "mensagem" deve ser entendida como fazendo parte de um processo comunicacional. Em outras palavras, a capacidade dos produtores em interpelar e convencer os seus leitores é diretamente proporcional à sua capacidade de incorporar/apresentar em seus textos elementos culturais próprios ao universo da recepção, que lhe permitam ver sentido no que é dito ou escrito. Assim, embora aquele que escreve tenha certa prioridade sobre aquele que lê - em termos bourdianos: a autoridade do poder de "escrita" -, o texto também deve ser compreendido como uma forma de diálogo, apesar de desigual. Nele podemos encontrar, mesmo que de maneira fragmentada, dispersa e minoritária, diferentes "falas", como nos indica o conceito de "polifonia", desenvolvido por Bakhtin (1987), que procura dar conta das "diversas vozes" presentes em um texto cujo autor está necessariamente inserido em um universo cultural repleto de intertextualidade. 


\section{Conclusão: imprensa, cidade e os anos 1950}

Como forma de conclusão, iremos fazer um balanço relacionando as considerações teóricas anteriores à análise do objeto de pesquisa específico que propomos considerar.

Em primeiro lugar, é importante salientar a própria pertinência de analisar as representações sociais ou coletivas que se geram sobre a cidade e as transformações urbanas em determinado período histórico: como vimos, devido a sua diversidade e pluralidade, as cidades são polissêmicas, ou seja, elas podem ser vistas e ditas de diferentes e contraditórias maneiras, e as formas como os indivíduos a significam e vivenciam não derivam apenas de suas experiências diretas com o urbano, mas fundamentalmente das representações que compartilham sobre ele. Em outras palavras, a forma como significamos e vivenciamos uma cidade depende da visão global que temos sobre ela e esta visão não se constitui apenas a partir de nossas experiências individuais diretas. Mas derivam fundamentalmente das representações existentes sobre ela, as quais tanto nos fornecem uma percepção panorâmica sobre o "todo urbano", quanto conduzem nossas experiências particulares sobre esse todo e suas partes.

Em segundo lugar - e como consequência do primeiro - está a importância de estudar essas representações a partir dos meios de comunicação: muito embora não sejam os jornais e os jornalistas os únicos produtores de bens simbólicos a fornecer "imagens" sobre as cidades, as representações acerca do urbano encontradas nos impressos têm a vantagem metodológica de serem aquelas que mais se difundiram em uma sociedade. Isso torna a imprensa uma fonte indispensável em qualquer pesquisa acerca do tema, quando não a mais importante. Ademais, os periódicos, acima de tudo, procuram apresentar uma interpretação pertinente - significativa e significadora - sobre a realidade dinâmica da urbs a seu público leitor e, para tanto, mais do que copiar ou reproduzir, eles se apropriam estrategicamente das formas simbólicas fornecidas por outros campos de produção. Em suma, estudar os jornais nos instrui, acima de tudo, acerca da constituição do "olhar jornalístico" sobre esse tópico, que, devido à sua própria pertinência, já se configura um tema de pesquisa bastante relevante.

Em terceiro lugar, é importante destacar a necessidade de compreender a narrativa jornalística a partir da sua condição de processo comunicacional - que incorpora a obrigatoriedade de um mínimo de diálogo entre o jornal/jornalista e seu público leitor. Essa perspectiva nos abre a possibilidade de desvelar, na análise dos diversos espaços de enunciação dos periódicos (editoriais, reportagens, colunas, artigos), diferentes vozes e percepções sobre o processo em curso, além daquela atribuída "oficialmente" ao órgão de imprensa por intermédio da identificação das visões de mundo incorporadas na narrativa jornalística pelo processo de interpelação dos leitores. Obviamente, não é tarefa fácil, exigindo um bom refinamento teórico-metodológico do pesquisador.

Por fim, considerando-se a tendência à segmentação da imprensa em diferentes 
públicos leitores e, ainda, levando-se em conta que os impressos do pós-guerra, no Brasil, eram jornais combativos e doutrinários - mesmo sem serem obrigatoriamente partidários -, a análise dessas "folhas" pode nos fornecer excelente material para compreender diferenças e contradições nas representações que se gestaram sobre a cidade e suas transformações nesse período. O que ganha maior validade quando recordamos que metrópoles, como o Rio de Janeiro, epicentro das principais transformações aqui abordadas, tinham uma grande variedade de periódicos diários, voltados a diferentes públicos e, muitas vezes, com inclinações doutrinárias e políticas distintas - como nos casos do Correio da Manhã, do Diário de Notícias, da Última Hora, da Tribuna da Imprensa e do Jornal do Brasil. Em outras palavras, o estudo desses jornais pode oferecer excelentes subsídios para entendermos as lutas de representação que se travaram na cena pública brasileira e carioca acerca das profundas mudanças que o país e a Capital Federal então passaram em decorrência da rápida urbanização-industrialização do período. Lutas de representação que englobaram visões de mundo, preconceitos, imaginários sociais e projetos para o futuro da Nação, mas também interesses econômicos e políticos variados.

Entretanto, devemos alertar que o emprego dessa abordagem teórica ainda exige uma exaustiva reflexão metodológica por parte do pesquisador, que, devido aos limites deste artigo, não poderemos desenvolver. Por ora, é suficiente lembrar que o estudo do discurso jornalístico, em qualquer época, não pode prescindir de uma análise social, econômica e cultural das suas condições de produção. Como demonstra os estudiosos da discursividade, considerar elementos próprios à linguagem e à interdiscursividade de um período é fundamental para entendermos o sentido de expressões e de ideias, de conceitos atuantes em um texto. Mas, levar em conta elementos externos à linguagem, como a extração social e os vínculos políticos-ideológicos dos produtores (jornalistas, editores, proprietários), a condição social e cultural dos leitores, os interesses e estratégias dos anunciantes e as próprias formas historicamente datadas de confecção, circulação e consumo dos impressos é fundamental para se entender o significado atuante do que está escrito em suas páginas.

Diante dessa proposta, como está o estado da arte das pesquisas sobre imprensa e cidade nos anos 1950, em especial, no Rio de Janeiro? Como já apontamos, o foco da historiografia que aborda a temática cidade-história-imprensa está direcionado à passagem do século XIX para o XX e não privilegia o pós-guerra, embora as mudanças no panorama urbano desse último período tenham sido tão ou mais impactantes do que as da Belle Époque. Por outro lado, os principais enfoques dos estudos históricos sobre os meios de comunicação nas décadas de 1950 e 1960 priorizam a condição dos jornais como agentes políticos frente aos diferentes governos que se sucederam na época - especialmente Vargas e Goulart (LAURENZA, 1998; GOLDENSTEIN, 1987; HAUSEN, 2001; ABREU; LATTMAN-WELTMAN, 1994) - e o processo de modernização pelo qual passou a imprensa ao adotar alguns 
princípios do jornalismo anglo-saxão (GOLDENSTEIN, 1987; RIBEIRO, 2007; ABREU; LATTMAN-WELTMAN, 1996). Pesquisas que abordam as transformações urbanas a partir dos jornais são muito escassas e normalmente utilizam a imprensa apenas como fonte, e não como objeto de pesquisa, dedicando-se mais à coleta de informações nos jornais do que propriamente à análise sobre a visão que produziram e difundiram a respeito do processo em curso (VALLADARES, 2000, 2005; ABREU, 1987, 2014; ALMEIDA; NAJAR, 2012).

Em síntese, o emprego da imprensa como fonte ou mesmo objeto de pesquisa para compreender a forma como as rápidas e impactantes transformações do período foram representadas - e, assim, simbolicamente experimentadas - ainda é um campo aberto para pesquisa. Nesse sentido, a iniciativa do projeto Cidades refletidas: industrialização, urbanização e imprensa no Brasil Republicano 4 procura atender, mesmo que parcialmente, essa lacuna, tendo como objeto central de análise a maneira como as mudanças nas principais cidades brasileiras (notadamente São Paulo e Rio de Janeiro) foram concebidas e significadas pelo grande imprensa do centro do país.

Apesar de seu caráter incipiente, esta pesquisa já apresenta resultados interessantes, mostrando, por exemplo, que no caso do Rio de Janeiro o processo de modernização gerou mais reações negativas do que era inicialmente esperado, havendo severas críticas ao processo de crescimento "desordenado" da cidade e ás mudanças viárias urbanas necessárias para comportar a indústria automobilística instalada no perío- do (MARTINS, 2015). Para esses jornais, tal processo descaracterizava o Rio de Janeiro como a Cidade Maravilhosa da Belle Époque, ao torná-la uma cidade industrial moderna e indiferenciada das demais. Um dos aspectos que chama mais atenção nesse processo foi a preocupação com o acentuado incremento das favelas, representado pelos principais jornais cariocas como um avanço de uma "cidade afro-brasileira" (a favela, seus habitantes de origem africana e sua cultura específica), ainda vivendo em um estágio de "barbárie" ou pré-civilizacional, contra a cidade educada, europeia, civilizada. O que levou certas folhas, como o Jornal do Brasil, a defender o cercamento da cidade a fim de evitar a entrada de mais migrantes, notadamente nordestinos. Entretanto, mesmo nesse tema, encontram-se divergências, havendo jornais, como a Última Hora, mais favoráveis ao processo de expansão urbano-industrial e que até tentaram se construir como porta-vozes dos favelados, dando espaço às suas reivindicações por melhores condições de moradia. Enfim, temos a configuração de uma verdadeira luta de representações, que permite identificar tanto os diferentes projetos que se elaboraram para a cidade, como a forma com que ela foi construída e percebida simbolicamente por boa parcela da população leitora dos jornais (MARTINS; KRILOW, 2015).

Entretanto, apesar desses resultados, é importante apontar alguns limites da análise proposta encontra. O primeiro está que, mesmo apresentando certa diversidade, a imprensa carioca e a brasileira estavam longe de serem isentas e de comportarem todos os pontos de vistas possíveis. Sobre 
os impressos exerciam-se - assim como ainda se exercem - vários tipos de pressão (anunciantes, partidos, governo, público leitor, etc.), que, muitas vezes de forma direta, outras indiretamente, influenciavam nas escolhas estratégicas dos jornalistas. O segundo limite está no fato de os periódicos impressos terem uma capacidade de circulação limitada no Brasil do pós-guerra, restringindo-se aos cidadãos alfabetizados e a seus próximos, o que excluía boa parte da população brasileira do acesso a sua leitura. Criar e editar uma folha de grande circulação também não era tarefa fácil, exigindo um alto investimento financeiro. Dessa forma, a atividade de impressão e de leitura de jornais estava longe de ser democratizada e plural, restringindo-se, na maior parte das vezes, aos extratos superiores da sociedade que eram os que escreviam e liam sobre o Brasil e o Rio de Janeiro no período. Decorre daí que, em estudos desse tipo, a tendência é encontrarmos, primordialmente, as representações produzidas sobre as cidades a partir da ótica da elite e da classe média letrada, as quais comportam, acima de tudo, visões, anseios, esperanças e projeto com um profundo "sotaque de classe". Entretanto, mesmo nesse caso, a pesquisa ainda é relevante, por permitir abordar as visões da elite e de parte significativa da sociedade acerca das mudanças em curso, que contribuíram para formar e conformar opiniões sobre elas e que também estavam sujeitas a contradições e escolhas.

Por fim, consideramos que a análise acima proposta apresenta pertinentes orientações sobre a importância da imprensa para o estudo das cidades brasileiras no século XX e sua complexa dinâmica econômico-social, oferecendo, ainda, alguns insights acerca da relação mais geral entre imprensa e cidade, ao menos no período estudado.

\section{Abstract}

The following paper analyzes of the stage of research studies that mingle press and Brazilian history, those studies which are focused on the Postwar period. It has been considered that this research area has developed immensily over the last few years, in what concerns the Brazilian cities during the Belle Époque. However, it has been perceived that this research field did not comprehend another historical periods where the empirical analisys have predominated over a more theoretical approach. The work presented here, which gets inspiration from concepts such as social representation (Chartier) and symbolic fights (Bourdieu), intends to promote a theoretical reflection on the importance of the press history studies in the Postwar period in order to augment our understanding about the always constant process of modern urban dynamics.

Keywords: City. Press. Representation.

\section{Resumen}

En este artículo se analiza el estado de los estudios sobre medios de comunicación y la historia de Brasil, el período posterior a la guera, cuando el país será sometido a profundas transformaciones urbanas. Se considera que la investigación han avanzado en los últimos años, 
con respecto a los cambios en las principales ciudades de Brasil durante la "Belle Époque". Sin embargo, se señala que dicha investigación no aborda otros períodos relevantes, y son más propensos a análisis empírico, con poco énfasis en la teorización. Por lo tanto, el trabajo aquí expuesto, a partir de los conceptos de representación social (Roger Chartier) y luchas simbólicas (Pierre Bourdieu), busca promover una reflexión teórica sobre la importancia del estudio de los medios de comunicación a la comprensión de la dinámica urbana en el proceso de transformación.

Palabras clave: Ciudad. Prensa. Representación.

\section{Notas}

1 Em 1940, temos 41.236.315 habitantes e, em 1960, passamos a ter 70.070 .457 , um aumento de aproximadamente $70 \%$ em duas décadas. Cfe. dados do Instituto Brasileiro de Geografia e Estatística, disponível em: <http://www.ibge.gov. br/home/estatistica/populacao/censohistorico/1940_1996.shtm>. Acesso em: 31 maio 2014.

2 Embora a noção já apareça em obras anteriores, a principal referência para o emprego da noção de representações coletivas é a obra Formas elementares da vida religiosa (DURKHEIM, 1996).

3 Para Bourdieu, por depender diretamente da extensão de seu público consumidor, o campo jornalístico é um dos campos de produção cultural de menor autonomia (1997, p. 76). O vínculo com o mercado implica em fortes constrangimentos sobre a produção jornalística, como a necessidade de atrair anunciantes e, em especial, de oferecer produtos capazes de expandir a clientela (BOURDIEU, 1997, p. 22-28). Além disso, existem todas as formas de pressão exercida pelo Estado e demais poderes públicos por meio das práticas de censura, alteração na legislação de imprensa e distribuição ou retenção de financiamentos (propaganda oficial, concessão de subsídios, etc.).

4 Essa pesquisa está sendo desenvolvida no Programa de Pós-graduação em História da Pontifí- cia Universidade Católica do Rio Grande do Sul, com financiamento da instituição e do Conselho Nacional de Desenvolvimento Científico e Tecnológico.

\section{Referências}

ABREU, Alzira. A.; LATTMAN-WELTMAN, Fernando. A imprensa em transição: o jornalismo brasileiro nos anos 50. Rio de Janeiro: Fundação Getúlio Vargas, 1996.

. Fechando o cerco: a imprensa e a crise de agosto de 1954. In: GOMES, Ângela (Org.). Vargas e a crise dos anos 50. Rio de Janeiro: Relume-Dumará, 1994. p. 23-60.

ABREU, Maurício de Almeida. Escritos sobre espaço e história. Rio de Janeiro: Garamond, 2014.

. A evolução urbana do Rio de Janeiro. Rio de Janeiro: Iplanrio. Jorge Zahar, 1987.

ALDÉ, Alessandra. Imprensa e política no segundo governo Getúlio Vargas. Redes, Rio de Janeiro, v. 1, n. 3, set./dez. 1997.

ALMEIDA, Fernando Henrique Bomfim. Bonde versus automóveis: um approach radical. 2011. Trabalho de Conclusão de Curso (Graduação em Economia) - Faculdade de Ciências Econômicas - Universidade Federal da Bahia (UFBA), Salvador, 2011.

ALMEIDA, Aline; NAJAR, Alberto Lopes. Cidade Maravilhosa e cidade partida: notas sobre a manipulação de uma cidade deteriorada. Revista Rua, Campinas, v. 1, n. 18, p. 119-132, jun. 2012.

BAKHTIN, Mikhail Mikhailovich. A cultura popular na Idade Média e no Renascimento: o contexto de François Rabelais. São Paulo: Hucitec; EdUnB, 1987.

BARBOSA, Marialva Carlos. História cultural da imprensa - Brasil (1900-2000). Rio de Janeiro: MAUADX, 2007. v. 1.

BOURDIEU, Pierre. La distantion. Paris: Minuit, 1979. 
. A economia das trocas simbólicas. 2. ed. São Paulo: Perspectiva, 1987.

. Coisas ditas. São Paulo: Brasiliense, 1990.

. L'emprise du journalisme: la recherche en sciences sociales. Actes, Paris, n. 101102, p. 3-9, mars 1994.

. Espaço social e espaço simbólico. In: RAZÕES práticas: sobre a teoria da ação. Campinas: Papirus, 1996.

. O poder simbólico. Lisboa: Perspectiva, 1989. Zahar, 1997.

Sobre a televisão. Rio de Janeiro: Jorge

BRESCIANI, Stella (Org.). Palavras da cidade. Porto Alegre: Ufrgs, 2001.

CHALABY, Jean. O jornalismo como invenção anglo-americana: comparação entre o desenvolvimento do jornalismo francês e anglo-americano (1830-1920). Revista Media E Jornalismo, Lisboa, n. 3, p. 29-50, 2003.

CHARTIER, Roger. À beira da falésia: a história entre incertezas e inquietude. Tradução de Patrícia Chittoni Ramos. Porto Alegre: Editora Ufrgs, 2002.

CRUZ, Heloísa. São Paulo em papel e tinta: periodismo e vida urbana 1890/1915. 2. ed. São Paulo: Arquivo Público do Estado de São Paulo, 2013.

DURKHEIM, Émile. As formas elementares da vida religiosa: o sistema totêmico na Austrália. São Paulo: Martins Fontes, 1996.

FERENCZI, Thomas. L'invention du journalisme en France: naissance de la presse moderne à la fin du XIXème siècle. Paris: Plon, 1993.

GOLDENSTEIN, Gisela. Do jornalismo político à indústria cultural. São Paulo: Summus, 1987.

GUINZBURG, Carlo. Olhos de madeira. Tradução de Eduardo Brandão. São Paulo: Companhia das Letras, 2001.
HAUSEN, Dóris. Rádio e política: tempos de Vargas e Perón. 2. ed. Porto Alegre: EdiPUCRS, 2001.

LAURENZA, Ana M. A. Lacerda $x$ Wainer: o corvo e o bessarabiano. 2. ed. São Paulo: Senac, 1998.

MARTINS, Luis Carlos dos Passos. Urbanização, industrialização e favelas: o Rio de Janeiro na imprensa carioca no Segundo Governo Vargas. Projeto História, São Paulo, n. 53, p. 210226, maio/ago. 2015.

MARTINS, Luis Carlos dos Passos; KRILOW, Letícia Sabina Wermeier. Cidades em transformação: industrialização, urbanização e imprensa nos anos 50. In: COLÓQUIO INTERNACIONAL DE HISTÓRIA CULTURAL DA CIDADE SANDRA JATAHY PESAVENTO, 1, 2015, Porto Alegre. Anais eletrônicos... Porto Alegre, 2015.

MARTIN-BARBERO, Jesús. Dos meios às mediações: comunicação, cultura e hegemonia. Rio de Janeiro: UFRJ, 1997.

MORAES, José Geraldo Vinci de. Ambiguidades da modernização urbano-industrial no Brasil Republicano (fins do século XIX - início do século XX). In: REGO, José Márcio; MARQUES, Rosa Maria (Org.). Formação econômica do Brasil. São Paulo: Saraiva, 2011. p. 145-176.

OLIVEIRA, Lúcia Lippi (Org.). Cidade: história e desafios. Rio de Janeiro: Fundação Getúlio Vargas, 2002.

OLIVEN, Ruben. Urbanização e mudança social no Brasil. Rio de Janeiro: Vozes, 1988.

PATARRA, Neide. Dinâmica populacional e urbanização no Brasil: o período pós-30. In: FAUSTO, Boris (Org.). História geral da civilização brasileira. Tomo III, v. 4. São Paulo: Difel, 1978. p. 249-268.

PESAVENTO, Sandra Jatahy. O imaginário da cidade: visões literárias do urbano - Paris, Rio de Janeiro, Porto Alegre. 2. ed. Porto Alegre: Editora Ufrgs, 2002. 
PESAVENTO, Sandra Jatahy; SOUZA, Célia Ferraz de (Org.). Imagens urbanas: os diversos olhares na formação do imaginário urbano. 2. ed. Porto Alegre: Editora Ufrgs, 2008.

PITKIN, Hanna Fenichel. Representação: palavras, instituições e ideias. São Paulo: Lua Nova, 2006.

RIBEIRO, Ana Paula Goulart. Imprensa e história no Rio de Janeiro dos anos 50. Rio de Janeiro: E-papers, 2007.

SEVCENKO, Nicolau. História da vida privada no Brasil República: da Belle Époque à Era do rádio. São Paulo: Companhia das Letras, 2006.

SINGER, Paul. Economia política da urbanização. São Paulo: Brasiliense, 1985.

VALLADARES, Lícia. A gênese da favela carioca. Revista Brasileira de Ciências Sociais, São Paulo, v. 15, n. 44, p. 5-34, out. 2000.

. A invenção da favela: do mito da origem a favela.com. Rio de Janeiro: FGV, 2005. 